\title{
AN EXPLORATION OF TINTO'S INTEGRATION FRAMEWORK FOR COMMUNITY COLLEGE STUDENTS
}

\author{
Melinda Mechur Karp \\ Katherine L. Hughes \\ Lauren O’Gara \\ Community College Research Center \\ Teachers College, Columbia University
}

May 2008

CCRC Working Paper No. 12

Address correspondence to:

Melinda Mechur Karp, Senior Research Associate

Community College Research Center

Teachers College, Columbia University

525 West $120^{\text {th }}$ Street, Box 174

New York, NY 10027

Mechur@tc.edu

212-678-3430

Funding for this study was provided by the Alfred P. Sloan Foundation. 


\begin{abstract}
Tinto’s integration framework is often assumed to be inapplicable to the study of student persistence at community colleges because one of the linchpins of the framework - social integration — is considered unlikely to occur for students at these institutions. Community college students are thought to lack the time to participate in activities, such as clubs, that would facilitate social integration. Using in-depth interviews with students at two urban community colleges in the Northeast, we examine the ways that first-year community college students engage with their institutions. We find that the majority of them do develop attachments to their institutions. Moreover, this sense of attachment is related to their persistence in the second year of college. We also find that this integration is both academic and social. Contrary to findings from other studies that apply Tinto’s framework, we find that these two forms of integration develop in concert for community college students. The same activities lead to both academic and social relatedness. This is particularly true for information networks that students develop in the classroom.
\end{abstract}




\section{Table of Contents}

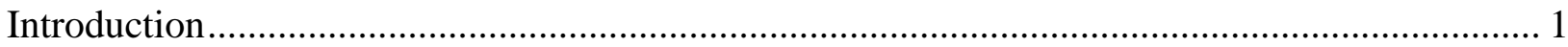

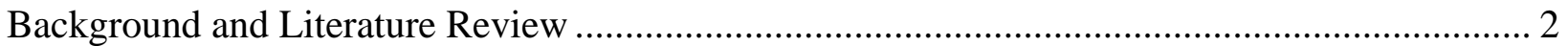

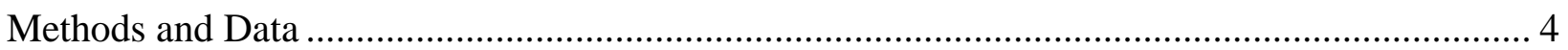

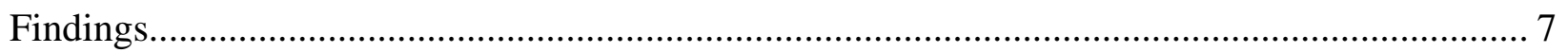

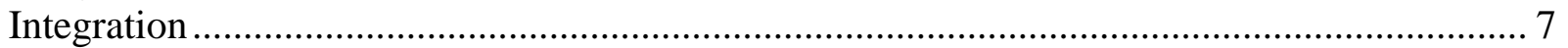

The Importance of Information Networks ............................................................................ 8

Where Do Information Networks Come From? .................................................................... 13

Information Networks Can Promote Academic and Social Integration Simultaneously ......... 16

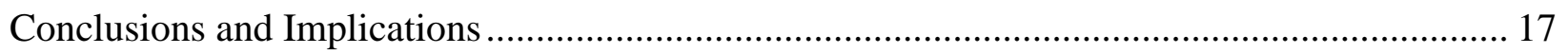

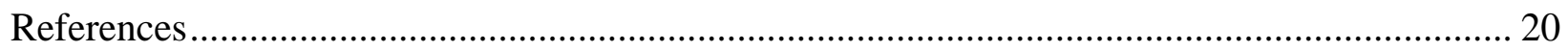




\section{Introduction}

Community colleges have long provided access to higher education for Americans who would not otherwise be able to attend college. Unfortunately, for many community college students, access to postsecondary education does not translate into the attainment of postsecondary degrees. For example, of first-time students entering community colleges during the 1995-1996 school year, less than half earned a degree or certificate or transferred to a fouryear institution within six years (Horn \& Nevill, 2006). Thus, scholars of the community college are focused on understanding ways to improve student persistence in these institutions.

Though commonly used to examine student persistence in the four-year sector, Tinto’s integration framework (1993) is often assumed to be inapplicable to two-year and commuter institutions. This is because one of the linchpins of the framework - social integration - is generally considered an unlikely thing for students at these institutions to attain. By nature of their attendance patterns - they attend class on campus but live elsewhere, often work full-time, and have strong familial obligations off-campus - community college students are assumed to lack the time to participate in activities, such as clubs, that would facilitate social integration.

This paper interrogates this assumption and finds it lacking. First, we find that integration is an important construct for understanding the experiences of beginning community college students. We use in-depth interviews with students at two urban community colleges in the Northeast to examine the ways that first-year community college students engage with their institutions and the unique challenges they face. We find that the majority of them do develop attachments to their institutions. Moreover, this sense of attachment is related to their persistence in the second year of college. Second, we find that this integration is both academic and social. Contrary to typical studies invoking Tinto’s framework, we find that these two forms of integration develop in concert for community college students. The same activities lead to both academic and social relatedness. This is particularly true for information networks that students develop in the classroom. 


\section{Background and Literature Review}

For many students, community colleges are the primary means of entry into the higher education system. Because of their convenient locations, open-access admission policies, and relatively low costs, community colleges tend to enroll students who are more academically, economically, and socially disadvantaged than do other postsecondary institutions. For example, nearly 30 percent of community college students are Black or Hispanic, as compared to 20 percent of students enrolled in four-year public and private postsecondary institutions (Horn \& Nevill, 2006). Approximately one-fourth of community college students come from families earning 125 percent or less of the federal poverty level, as compared to one-fifth of four-year college students (Horn \& Nevill, 2006). And entering first-year students at community colleges are more likely to take at least one remedial course than are their peers at four-year colleges, and they are more likely to spend a longer time taking such courses (U.S. Department of Education, National Center for Education Statistics, 2004).

Student success at these institutions remains low. After six years of enrollment, only 45 percent of community college students earn a certificate or degree or transfer to a four-year institution (Bailey, Jenkins, \& Leinbach, 2006). While 8 percent of students remain enrolled, 47

percent leave school without earning a credential. Although these statistics include some students who enter the community college with goals other than degree attainment or transfer, it is clear that many community college students do not persist toward an educational credential, despite considerable efforts by the institutions to support student progress.

Community colleges are not the only institutions of higher education that struggle with unsatisfactory rates of student persistence, though they are perhaps the most dramatic example. Many authors have tried to explain why students might not attain a postsecondary degree, even after professing a desire to do so and enrolling in college (Bean, 1980, 1982; Manski, 1989; Pascarella, 1985; Tinto, 1993). One of the most popular theoretical perspectives regarding this issue is Tinto's integration framework (1993).

Tinto posits that students are more likely to remain enrolled in an institution if they become connected to the social and academic life of that institution. Students who become integrated into a college, by developing connections to individuals, participating in clubs, or engaging in academic activities, are more likely to persist than those who remain on the 
periphery. Preventing this integration process may be incongruence, or a lack of institutional fit. Students who do not feel at home in an institution or do not believe that an institution can help them meet their goals are unlikely to persist. Likewise, students who are isolated, or who do not engage in social interactions within the college, are less likely to persist in the institution. Both incongruence and isolation inhibit the integration process, thereby inhibiting persistence.

Tinto points out that student integration into an institution can occur along two dimensions, the academic and the social. Academic integration occurs when students become attached to the intellectual life of the college, while social integration occurs when students create relationships and connections outside of the classroom. These two concepts, though analytically distinct, interact with and enhance one another. And, while students must be integrated into the institution along both dimensions to increase their likelihood of persistence, they need not be equally integrated along the two. Likewise, Tinto notes that there are both formal and informal systems within institutions that can encourage integration and persistence.

Tinto’s framework has been applied to myriad studies of student persistence in postsecondary education. Its usefulness for community college students, however, has been questioned, as it is assumed that community colleges provide students with fewer opportunities for social integration and that the social aspect of postsecondary education may be less appealing to students attending two-year commuter institutions. Tinto himself has questioned whether the mechanisms that encourage social integration in particular are relevant to community college and commuter students (1993, p. 78).

Moreover, one typical institutional response to Tinto’s work has been to implement structured student support services meant to encourage integration. Community colleges in particular have taken this approach (see Bailey \& Alfonso, 2005, for a review of these initiatives in community colleges). The underlying assumption is that if colleges provide enough structured opportunities for students to engage with the institution, students will become integrated into the college and persist at higher rates. However, as evidenced by the continuing low levels of persistence at these institutions, it is not clear that such efforts have been effective. Perhaps students do not know about these services, or do not make use of them. Or, perhaps, the concept of integration as a means to persistence has less relevance in the community college, therefore making efforts to create such integration moot. 
Some research, though, indicates that the framework is appropriate (Deil-Amen, 2005). Using data from the Beginning Postsecondary Students (BPS) Longitudinal Study, Deil-Amen found that measures of social integration were related to persistence for community college students, as were measures of academic integration. She also found that that the two constructs of integration may not be as distinct as is often assumed. For example, she argues that activities such as study groups leading to student integration can be considered both academic and social.

This paper extends Deil-Amen's work by interrogating Tinto's model as it relates to community college students. We explore the ways that integration does and does not occur in the community college, and we seek to understand whether academic and social integration are distinct constructs or interrelated. In doing so, we further refine the understanding of the integration and persistence process for community college students.

\section{Methods and Data}

We conducted an exploratory study of student persistence in community colleges to explore, among other things, what students report about their initial institutional experiences and the relationship between those experiences and progress toward a degree. We conducted interviews with community college students during their second semester of enrollment, ${ }^{1}$ and we re-interviewed them six months later, whether or not they remained enrolled. The participants in the study were students from two urban community colleges in the Northeast that enroll significant numbers of minority and economically disadvantaged students (we refer to these institutions by pseudonyms, Northern Community College [Northern CC] and Eastern Community College [Eastern CC]).

Students were randomly selected from a list of all first-time enrollees in fall 2005 who persisted to spring 2006. Non-matriculating and continuing education students, as well as those who already had earned a postsecondary degree elsewhere, were excluded. Letters of invitation to participate in the study were sent to 176 students; each potential participant was also contacted by telephone at least three times at various times of the day in an attempt to secure their

\footnotetext{
${ }^{1}$ Since we were interested in the progress of degree-seeking students, we interviewed only students who had persisted to a second semester of enrollment, thereby excluding those students who might be considered "experimenters" or who otherwise might not have had degree completion goals.
} 
involvement. Participants were offered a \$100 cash stipend (\$50 per interview). Due to a low take-up rate, we supplemented the sample using a snowball technique for the recruitment of additional students.

Forty-six students agreed to participate and were interviewed in the spring semester. Two students were later dropped from the sample because they did not meet the selection criteria, such that our final sample comprised 44 students from the two colleges. The top row of Table 1 shows the demographic characteristics of the sample.

During the summer and fall, multiple efforts, such as telephone calls, mailings, emails, and text messages, were made to maintain contact with the participants and then to schedule follow-up interviews. We were able to re-interview 36 of the 44 students in the original sample. The fall 2006 responses of the students in the sample, as well as responses by student demographics, are shown in the bottom three rows of Table 1.

The difficulty we had in recruiting and following up with students for the study, even while offering a cash stipend, may well be an indicator of the many barriers the students faced as they sought a postsecondary credential. Through phone conversations with students, we determined that in many cases, the low take-up and follow-up rates were due primarily to the many demands on students' time. Between school, work, and familial responsibilities, even an hour-long interview was impossible to schedule for many students. In addition, a significant number of students or their families did not speak English well and so did not understand the nature of the research or were reluctant to participate in an interview. 
Table 1:

First-Round Participants and Second-Round Responses by College and Demographics

\begin{tabular}{|c|c|c|c|c|c|c|c|c|c|}
\hline & \multicolumn{2}{|c|}{ College } & \multicolumn{2}{|c|}{ Gender } & \multicolumn{5}{|c|}{ Race } \\
\hline & $\begin{array}{l}\text { Eastern } \\
\text { CC }\end{array}$ & $\begin{array}{l}\text { Northern } \\
\text { CC }\end{array}$ & Female & Male & Black & White & Hispanic & $\begin{array}{l}\text { Asian/ } \\
\text { Pacific Islander }\end{array}$ & Unknown \\
\hline $\begin{array}{l}\text { First-round } \\
\text { participants } \\
(\mathrm{N}=44)\end{array}$ & 25 & 19 & 28 & 16 & 11 & 14 & 10 & 7 & 2 \\
\hline $\begin{array}{l}\text { Second-round } \\
\text { participants } \\
(\mathrm{N}=36)\end{array}$ & 21 & 15 & 22 & 14 & 8 & 13 & 8 & 6 & 1 \\
\hline $\begin{array}{l}\text { Unable to } \\
\text { Schedule* } \\
(\mathrm{N}=5)\end{array}$ & 3 & 2 & 4 & 1 & 3 & 0 & 0 & 1 & 1 \\
\hline $\begin{array}{l}\text { No } \\
\text { Response** } \\
(\mathrm{N}=3)\end{array}$ & 1 & 2 & 2 & 1 & 0 & 1 & 2 & 0 & 0 \\
\hline
\end{tabular}

* Participants who did not show up for a scheduled interview or those to whom we spoke but never scheduled a second interview in fall 2006.

** Participants who never responded to repeated phone calls and flyer attempts to schedule the second interview in fall 2006.

Both waves of data collection were recorded and transcribed for analysis and consisted of one approximately 60-minute semi-structured interview per student. The spring 2006 interviews focused on students' initial experiences in college. We asked about their reasons for enrolling; goals; first and second semester courses; perceptions of and experiences in their courses; their use and knowledge of student services, such as counseling and tutoring centers; and their relationships with classmates and professors. We also asked about the challenges participants foresaw in completing their degrees; where and from whom they sought and received support and information about the college; and what the college could do to make it easier for them to progress toward a degree. The fall 2006 interviews focused on students' decisions to continue in college or not, and the challenges they faced in progressing toward their degree goals. We probed, in particular, for how social and academic relationships, the knowledge and use of the institutional services available to them, and sense of comfort on campus contributed to their progress toward a degree or lack thereof.

The transcribed interviews were uploaded to NVivo, a software program for analyzing qualitative data. We created codes that addressed student perceptions of their courses and the presence of various social relationships. We coded students for their reported sense of belonging in the institution and the types of social networks to which they belonged. We also coded student 
attributes, including race, socioeconomic status, and gender, as well as student progress toward a degree.

We then read the interviews thematically, examining how students described various aspects of their college environments. For example, we read all transcript pieces related to course experiences, as well as all transcript sections related to information networks. We sought themes that emerged from the data.

\section{Findings}

\section{Integration}

We first sought to answer whether students in the sample reported being integrated into the institution. We defined integration as having a sense of belonging on campus. Analytically, this meant that students were coded as being integrated if they reported feeling comfortable on the campus or reported enjoying their time in college and/or their classes. Because we were interested in the relationship this sense of belonging had on progress toward a degree, we coded student integration based on data from their first interview (or after one full semester in college).

Thirty-one students, or 70 percent of the sample, reported feeling a sense of belonging on campus. Thirteen students reported nothing that indicated an attachment to the institution. Given Tinto's integration framework, we would expect that those students reporting a sense of belonging would be more likely to persist to their second year of enrollment. Of the 40 students whose enrollment status in fall 2006 was known to us, those who were coded as being integrated were more likely to persist: nearly 90 percent of students who were integrated into the college persisted to the second year, while just over two-thirds of those who were not integrated did so. (It should be noted that our sample had an unusually high rate of persistence overall.)

These findings support Tinto's theory that integration is related to persistence. They also refute the notion that integration is unimportant for community college students. We acknowledge, of course, that our sample is small and the study was exploratory; the findings require further research for confirmation. However, these findings indicate that our data warrant 
additional exploration to understand how such integration came about. How do students develop an attachment to an institution within the context of the community college?

\section{The Importance of Information Networks}

In analyzing the data thematically, it became clear that student participation in information networks was an important mechanism in encouraging integration. We defined information networks as social ties that facilitate the transfer of institutional knowledge and procedures. In other words, knowing people to say hello to in the hallways did not strongly influence students' sense of belonging; knowing people through whom one could learn about professors, course options, or support services did. The information networks in which students participated could include either professors or classmates, but they had to be made of ties that were strong enough to promote information gathering.

In our analysis, students were coded as being part of an information network if they met one of the following criteria: they had a specific individual on campus to whom they could go for information; they described using faculty or classmates to get information; or they described an information-seeking process that included college-based social relationships and/or information chains. Twenty-seven students in our sample (61 percent) reported engaging in an information network; 17 students (38 percent) reported that they did not.

Twenty-six of the 31 students who were coded as integrated into the college also reported being part of an information network (84 percent). One student of the 13 who were not integrated was part of a network (8 percent). It appears, then, that having an information network was related to being integrated into the college. ${ }^{2}$

Given this relationship, it is important to examine why information networks appear to have been so important in facilitating integration. Students reported using information networks in a variety of ways that made the campus feel more friendly and manageable, and which helped them overcome obstacles that could have resulted in alienation from or frustration with the

\footnotetext{
${ }^{2}$ Given the exploratory nature of the data, we cannot discern the direction of causality. However, given student reports of the importance of information in encouraging a sense of belonging on campus, we assume that these networks facilitate integration, not the reverse.
} 
institution. The result is that information networks appear to have helped students feel at home on campus while giving them the tools necessary for successful degree completion.

\section{Information networks and campus connections}

One of the primary ways students use information networks to encourage integration is to make connections throughout the campus. For many students, attending community college is a narrow experience. Because they commute to campus, college interaction is mainly limited to the classroom - they come to class and leave afterward. Thus, navigating the larger social space, learning about the resources available to them outside of the classroom, and feeling connected to the broader institution can be challenging.

Information networks help students overcome this obstacle. For example, students can learn about campus resources, such as tutoring or supplemental support programs, through networks of classmates. A student in our study, Emily $^{3}$ (Eastern CC), learned about the EOF program, which provides financial, academic, and social support to low-income and firstgeneration college students, from a network of her peers. She said, "I just heard [about] it from somebody that's in my class. I don't know if it's a secret, but it's not really out in the open. People hear about it from word of mouth, and they just happened to tell me.”

Similarly, when other students in our study learned about their campus through social relationships, rather than through printed materials or other forms of information, they reported feeling more comfortable actually using the resource. For example, most students in our sample participated in a Student Success course, intended to acclimate them to the college environment. As part of this course, professors gave students guided tours of the campus and introduced them to representatives from various offices and support services. A number of students reported feeling more comfortable taking advantage of these supports once they had developed relationships with support staff. Heidi (Northern CC) described this process when she said, "It was really interesting to see all the possibilities that you would probably not find out by yourself if you just walked through the college. But now you feel more comfortable; now you know the library and you know who to ask if you were looking for something."

Because students who engaged in information networks learned about and became comfortable on the campus, the campus felt "smaller" and more manageable. Their social

\footnotetext{
${ }^{3}$ All names are pseudonyms.
} 
connections extended beyond the confines of the classroom, and the social space of the institution became a familiar, welcoming one. They reported feeling less lost and more at home. Jonah (Eastern CC) summed up this benefit by saying, "Yea, if I don't talk to a student I can talk to my teacher. If I don't talk to my teacher I can turn to a counselor, it's endless. You can go from one person to another and each have different things or different parts to tell you."

\section{$\underline{\text { Information networks strengthen social connections }}$}

By definition, social networks contain relationships. Students in our study who engaged in information networks reported that these networks provided a social connection that made time on campus more enjoyable. These networks gave students a reason beyond pure academics to want to come to school. Explained Mike (Northern CC),

Someone will know about a certain event that you weren't aware of and they'll communicate that; you'll find out or whatever. Maybe you're not sure of a program here or something and maybe they know about it or have been involved with it. You could ask them and figure out a little more.

That social relationships lead students to want to come to school is not terribly surprising. What is interesting is that relationships predicated on information exchange appear to lead to stronger social connections than others. Most students in our sample, for example, differentiated between those students whom they knew in passing and those who were real friends. Typically, real friends provided information about course assignments, professors, and graduation requirements, while acquaintances were good for just chitchat. Debra (Eastern CC), for example, maintained that there was a difference between most of the people she knew in college and her one good friend, saying of the former, “I don't talk to them outside of class, only in class. I got some of their phone numbers just in case, but I don't use them." Her one good friend, on the other hand, gave Debra advice on professors, helped her learn things about the college, and made her feel comfortable there. "We go through the same experiences, the same feelings, of how we view school. We help each other on work.” Many students in the sample made a similar kind of differentiation between those professors with whom they interacted superficially (by sending homework via email, for example) and those with whom they engaged in more meaningful exchanges (by discussing career plans, for example). 
The relationships that comprised information networks, therefore, were more meaningful to students and helped create stronger attachments to the institution than those that did not serve to provide information. Knowing people well on campus made academic life "fun," but it also made it meaningful. The ties between persons in these networks were made stronger because they facilitated information exchange. Those in such networks had a stronger attachment to the institution.

\section{Information networks as a personal resource}

Many community college students report difficulty in receiving useful information about course registration, graduation requirements, and other particulars of the community college experience (Karp, O’Gara, \& Hughes, 2008; Community College Survey of Student Engagement, 2007). They also often report feeling uncertain of where to go with problems and concerns. The students in our sample who were part of information networks were less likely to report such difficulties, finding instead that such networks facilitated access to good information and helped them identify sources of support on campus. This, in turn, led them to feel confident in the decisions they were making and to believe that they belonged in college.

For example, students often used information networks to obtain better course advisement. In both colleges, the typical way of receiving course advice was to meet with a general college counselor who did not have an ongoing relationship with the student or to use printed college materials such as a course catalog. These methods often led to inadequate or inaccurate advice; they also left students without a sense of connection to the college. Eddy (Northern CC) described the process as "throwing darts at a board." Emblematic of this approach was Daria, another Northern Community College student. She used the catalog and described the process as quite easy. Though she received adequate information, the course selection process did not help her develop a sense of attachment to the institution, as using a course catalog did not involve a network of relationships. Without these information networks and connections to individuals at the college, she did not become integrated into the institution. Daria did not persist to her second year in college.

In contrast, students who were part of information networks gained high quality information about courses and felt more attached to the college. Mike (Northern CC), for example, developed relationships with faculty members in his department, whom he used to gain 
information about required courses. He had multiple conversations about his goals and his program of study, and he found that this helped him feel comfortable in his course decisions. He said, "You get to know them, and you form a relationship with them and get in contact with them. And they like you and, well, you feel like you have somebody in the system to help you out.” Mike not only received the necessary information, he also developed a sense that he belonged in the institution and that people in the college cared about him and his future.

Veronica (Eastern CC) was another student who epitomized the way that information networks gave students useful information while simultaneously increasing their sense of connection to the college. Veronica initially approached her psychology professor to get course advice, but the relationship soon blossomed into something more.

I would speak to her after class if I had a problem with something. She was just so helpful. And she made the class so interesting. I had no idea how fascinated with psychology I became. So I wanted to change my major, so I joined the psychology club, became the president of the psychology club, went away to Baltimore with her to the APA conference....

Students who were part of information networks also felt that, no matter what the college "threw" at them, they had someone to go to for help. The quoted material already presented in this section implies this as the students describe how course advising can transform into a broader ability to approach faculty about many different subjects. Jack (Northern CC) provides another example of this, describing the process of meeting with faculty members: "And what better way to get help but from an ex-teacher who knows about what I'm trying to become.... Now I know what I have to do, what classes to take. And now I know I have somebody there in case I'm ever in trouble with one of my classes."

All three benefits of information networks - campus connections, social contact, and personal resources - encourage students to feel connected to the college. They do this in large part because they help students develop trust in the institution. Students who engage in information networks begin to believe that there are people at the college who want them to succeed and who will help them try to reach their goals. Students who do not have these resources often feel adrift; they may feel as though the college does not care about their future. Students in our study often felt frustrated with their institutional experiences; indeed, they often expressed the belief that the college was set up to promote failure. Daria, the student discussed 
earlier who used a course catalog rather than information networks to select her classes, professed this belief when she explained her failure to persist.

Students who were part of information networks, in contrast, found that they could navigate the college and felt that they could find ways to overcome challenges. They trusted the information they received from the institution and generally believed that their interests were being supported by the college. As a result, they expressed comfort and a sense of belonging on campus, and thus were more willing to continue with their education, even as some of them faced significant academic difficulty.

\section{Where Do Information Networks Come From?}

Given their importance in encouraging integration, it is important to ask how students develop information networks and whether these networks encourage social or academic integration. In other words, do these networks come from academic locations or from social ones? Tinto’s framework would predict that, for community college students, integration would stem from academic sources as community college students are unlikely to participate in social activities on campus.

Our data support the framework to some extent. Students generally develop information networks through academic sources. Moreover, those students who do create networks through extracurricular activities do not generally receive the same benefits in terms of information and integration as students whose networks are established in academic settings.

Students in our sample generally developed their information networks within the classroom. For many of them, these networks began in a class specifically designed to encourage persistence in college — the College 101 or Student Success course. This one-credit course is conceived of as a way to orient students to college, provide them with information about the college, and help them develop skills that will encourage success. And students who took the class reported receiving these benefits from their participation (O’Gara, Karp, \& Hughes, 2008).

An unintended consequence of the course was that its structure and content facilitated the development of information networks, which further encouraged integration. Leroy (Northern CC) described the resulting integration succinctly, saying that the course was the class that "got 
you into college.” His use of the word “into” strongly indicates that he felt integrated, or attached, to the institution after taking the Student Success course.

Student Success encouraged the development of information networks in a number of ways. First, the content of the course exposed students to a variety of staff members and helped them identify individuals to include in their networks. This was facilitated by having guest speakers come to class as well as through guided tours of college offices. As noted above, such experiences helped students feel comfortable approaching personnel in these offices and gave them a "touchstone" when they were seeking help.

Second, the course included a variety of group projects and discussions that facilitated the development of peer networks. The focus of these networks was on academic rather than peer culture. In most sections of the course, for example, students were graded on their participation, the result being that they had to engage with other students. Eddy (Northern CC) described the Student Success course as encouraging students to “crack that shy shell.” His comments suggest that the course was structured to encourage the creation of networks: "He'd have us work more in groups ... and you've got to talk to the person next to you, and we're all laughing; it was like, this isn't that bad.... I think that really helps.”

Third, the course provided students with a clear faculty member to use as a resource for guidance and support. Many students described how they used their Student Success professor as their main resource for information and connectedness on campus. The structure of the course encouraged interactions between students and professors, so students felt that their Student Success professors knew them and their goals well. This enabled the Student Success professors to give students individualized course advice, which was greatly appreciated. Because students had a relationship with and trusted their professors, they often sought them out after the course ended. Jasmine (Northern CC), for example, continued to meet with her Student Success professor long after the course ended, saying, "She’s sort of like my go-to person now."

The other way that information networks were facilitated was through student-centered pedagogies used in many classrooms. Here our findings mirror some of Tinto's later work on classrooms as communities (Tinto, 1997). For many students in our study, the ability to connect with peers and professors through classroom discussion was an important mechanism for developing social relationships that could be used to access information and develop an 
attachment to the college. These relationships tended to be grounded in the academic discipline of the course, and they helped students to feel that they were part of an academic community.

Classroom pedagogies encouraged these networks in a number of ways. First, some professors viewed the campus as a laboratory, encouraging students to use it as a base for their academic study. Catherine (Northern CC), for example, described how one of her professors required students to interview staff and faculty members in the completion of some course assignments. This encouraged her to learn about the campus and to discover many interesting things about the college she would not have otherwise. She said, "You just find out these really amazing things from this class because you're forced to constantly talk to, like, the president of the school or the dean of students ... and it's really great.” Throughout her interview, Catherine expressed great enthusiasm for her school.

Classes that encouraged discussion also appeared to facilitate information networks and, ultimately, integration. Many students in the sample commented on the ways that their professors encouraged discussion in class and how these discussions helped them learn about the campus and become more comfortable on it. Asha (Eastern CC), for example, described class discussions by saying, "When you're having a group discussion you tend to interact invariably and that interaction leads to friendship.” Another Eastern CC student, Carla, expanded upon this by explaining how these friendships can lead to information. "Also, for knowing what good professors to take I rely on my classmates' opinions because a lot of them have been here longer than I have or they've had to repeat a class or something like that.”

Thus, student-centered pedagogies appear to help students interact with one another enough to create social networks that can be used to access information. This, as we have discussed, creates a sense of belonging and attachment that seems to encourage persistence. Interestingly, networks that were created outside of the classroom - which were therefore focused more on the social aspect of college than on providing information about academics did not seem to serve this purpose. A few students in our sample were actively involved in clubs and activities. These students, however, did not display a high degree of integration. In fact, one of the students who was most involved in such activities and who knew many people on campus was one of the least successful students in our sample. This student, despite his apparent involvement in campus life, had no information networks, was not integrated into the campus, 
and did not persist to a second year. Thus, it appears that the number of ties a student has is less important than the content of those ties.

\section{Information Networks Can Promote Academic and Social Integration Simultaneously}

Most interpretations of Tinto’s integration framework conceive of academic and social integration as developing in separate spheres and as forming discrete constructs (Braxton, Milem, \& Sullivan, 2004; Hurtado, Carter, \& Spuler, 1996; Nora, Cabrera, Hagedorn, \& Pascarella, 1996). This is one reason why the framework is seen as inappropriate for community college students. However, our data support the alternate view that for these students the academic and the social are intertwined. In this way, we support and extend Deil-Amen’s previous work on the topic (Deil-Amen, 2005).

As noted, social integration, as traditionally conceived, did not occur for the students in our sample. Students who participated in "social" activities, such as clubs or student government, did not necessarily develop strong ties to the institution. However, this is not to say that students did not develop social relationships or social integration. Many students did have relationships that extended beyond the classroom. They usually had one or two friends with whom they spoke on the telephone or they had classmates to study with. Some even met with professors outside of class for a cup of coffee.

These relationships, however, began as academic relationships and were rooted in academic processes. For example, a number of students said that they found study groups to be academically helpful, but that they were a social outlet as well. Other students described their relationships in the following ways.

If an assignment is interesting and if our discussion goes into debate, we do continue that conversation after class. (Alan, Eastern CC)

We do have group projects that we work on. We usually work on those like after class, as long as we don't have any classes after that one.... It's fun. You get to know people, just get to know what they're about and how they work. (Lindsey, Northern CC)

Yea, like yesterday when I was in Anatomy and Physiology, I heard one of the girls say that they were giving a nursing seminar ... so being that they're giving a seminar I'd like to go and find out different things. (Rashida, Eastern CC) 
For all of these students, relationships forged in class extended beyond the classroom. It is not easy to disentangle the ways in which these relationships lead to academic integration versus social integration; the two are very much connected. For many community college students, this is a necessity, as they do not have time to engage in purely social pursuits. Cal (Northern CC) eloquently summed up this process when he described his social networks:

We try and help each other as best we can. It's not only social, but it's academic. We try and figure out where we can help each other. And when you focus with a peer on helping each other, it's a more personal thing. So that way when someone knows you, they know how to help you. So it is a lot more involved.

Thus, our data demand that Tinto’s framework be reconceptualized for community college students. They require that we shape our understanding of the integration process into one that encompasses both the academic and the social. The two do not appear to be analytically distinct for these students. Instead, academic processes can lead to social relationships. Future research on the persistence of community college students should take this into account.

\section{Conclusions and Implications}

In sum, we find that beginning community college students do become integrated into the college environment, as indicated by the reported sense of belonging by students in our sample. As predicted by Tinto's integration framework and in similarity with research findings on students attending four-year institutions, integration is related to community college students’ persistence. Moreover, as argued by many authors, community college students rarely experience social integration as a result of participating in activities such as clubs.

We found that student integration is developed through participation in information networks. These networks allow students to navigate the campus environment, access knowledge about the college, create a sense of social belonging, and, ultimately, feel that there are people who care about their academic welfare. It is important to note that these networks are not merely a collection of social ties. The social ties provide opportunities to gain specific pieces of information, which in turn encourage integration and ultimately persistence. 
These networks are developed through classroom structures. These may include specific courses, such as Student Success, which help students learn about the college and initiate relationships that can provide them with information, as well as broader pedagogical decisions, such as using student-centered pedagogies or promoting classroom discussions. Moreover, the relationships and networks that develop through these classroom-based activities encourage academic and social integration. We found that, for community college students, the two constructs are not distinct. Instead — and in contrast with much that has been written using Tinto's framework - the two forms of integration are developed simultaneously, through the same activities. Classroom discussions, for example, help students feel academically connected to the college while also promoting relationships that can be used to access information and that extend to social activities outside of the classroom.

This study has important theoretical implications. First, it illustrates that, to some extent, Tinto’s theory may apply to community college students. It is therefore appropriate to examine student persistence in the community college using an integration framework.

Second, it lends credence to Deil-Amen's notion that social and academic integration may look different in the community college than in residential four-year institutions. Community college students may achieve both forms of integration, but may do so in ways that are different from, and perhaps more fluid than, other students. As such, future research should seek ways to create analytic constructs that account for both types of integration. Studies of integration in the community college should not ignore social integration, but should examine the ways in which social integration is encouraged by academic activities. Moreover, because the academic and the social are intertwined, disentangling the influence of each poses an analytic challenge that future researchers should examine.

Finally, there is no reason to assume that the interconnected nature of academic and social integration is limited to community college students. Those attending residential four-year institutions and commuter institutions may also engage in activities that promote both types of integration. Students in residential schools, for example, may also benefit from student-centered pedagogies and the creation of information networks. Thus, future research should examine integration processes as they relate to traditional college students, and use those findings to expand our conception of integration for all students. 
For practitioners, the findings indicate that integration is related to persistence, and as such should be encouraged. Because much of this integration occurs in the classroom, practitioners should find ways to structure students' academic activities so that they promote the development of information networks. In particular, Student Success courses should be required of all beginning students. In addition, student-centered pedagogies should be encouraged. Finally, professors should be supported in their efforts to work individually with students in order to further develop their potential as information sources. 


\section{References}

Bailey, T., \& Alfonso, M. (2005). Paths to persistence: An analysis of research on program effectiveness at community colleges. Indianapolis, IN: Lumina Foundation for Education.

Bailey, T., Jenkins, D., \& Leinbach, T. (2006). Is student success labeled institutional failure? Student goals and graduation rates in the accountability debate at community colleges (CCRC Working Paper No. 1). New York: Columbia University, Teachers College, Community College Research Center.

Bean, J. P. (1980). Dropouts and turnovers: The synthesis and test of a causal model of student attrition. Research in Higher Education, 12(2), 155-187.

Bean, J. P. (1982). Student attrition, intentions, and confidence: Interaction effects in a path model. Review of Educational Research, 55, 485-540.

Braxton, J. M., Milem, J. F., \& Sullivan, A. S. (2004). The influence of active learning on the college student departure process: Toward a revision of Tinto's theory. The Journal of Higher Education, 71(5), 569-590.

Community College Survey of Student Engagement (2007). Committing to student engagement: Reflections on CCSSE's first five years. Austin, TX: University of Texas at Austin, Community College Leadership Program.

Deil-Amen, R. (2005). Do traditional models of college dropout apply to non-traditional students at non-traditional colleges? Paper presented at the annual meeting of the American Sociological Association, Philadelphia, PA.

Horn, L., \& Nevill, S. (2006). Profile of undergraduates in U.S. postsecondary education institutions: 2003-04: With a special analysis of community college students (NCES 2006184). U.S. Department of Education. Washington, DC: National Center for Education Statistics.

Hurtado, S., Carter, D. F., \& Spuler, A. (1996). Latino student transition to college: Assessing difficulties and factors in successful college adjustment. Research in Higher Education, 37(2), 135-157.

Karp, M. M., O’Gara, L., \& Hughes, K. L. (2008). Do support services at community colleges encourage success or reproduce disadvantage? An exploratory study in two community colleges (CCRC Working Paper No. 10). New York: Columbia University, Teachers College, Community College Research Center.

Manski, C. F. (1989). Schooling as experimentation: A reappraisal of the postsecondary dropout phenomenon. Economics of Education Review, 8(4), 305-312. 
Nora, A., Cabrera, A., Hagedorn, L. S., \& Pascarella, E. (1996). Differential impacts of academic and social experiences on college-related behavioral outcomes across different ethnic and gender groups and four-year institutions. Research in Higher Education, 37(4), 427-451.

O’Gara, L., Karp, M. M., \& Hughes, K. L. (2008). Student Success courses in the community college: An exploratory study of student perspectives. (CCRC Working Paper No. 11). New York: Columbia University, Teachers College, Community College Research Center.

Pascarella, E. T. (1985). College environmental influences on learning and development: A critical review and synthesis. In J. C. Smart (Ed.), Higher education: Handbook of theory and research, Vol. 1 (pp. 1-61). New York: Agathon.

Tinto, V. (1993). Leaving college: Rethinking the causes and cures of student attrition ( $2^{\text {nd }}$ ed.). Chicago: University of Chicago Press.

Tinto, V. (1997). Classrooms as communities: Exploring the educational character of student persistence. The Journal of Higher Education, 68(6), 599-623.

U.S. Department of Education, National Center for Education Statistics. (2004). The condition of education 2004 (NCES 2004-077). Washington, DC: U.S. Government Printing Office. 